\title{
Germination and Growth Studies of Abelmoschus esculentus L. Moench in Palm Bunch Ash Extract of Elaeis guineensis Jacq. Supplemented Medium
}

\author{
${ }^{1}$ Etukudo, Mbosowo. M., ${ }^{2}$ Udo, Joseph I. and ${ }^{3}$ Okereke, Ifeoma. J. \\ ${ }^{I}$ (Department of Biological Sciences, Federal University Otuoke, P.M.B. 126, Yenagoa, Bayelsa State, Nigeria) \\ ${ }_{2}^{2}$ (Department of Plant Science and Biotechnology, University of Port Harcourt, Rivers State, Nigeria) \\ ${ }^{3}$ (Department of Environmental Resource Management, Abia State University, Uturu, Abia State, Nigeria)
}

\begin{abstract}
Laboratory studies of germination and growth parameters of Abelmoschus esculentus L. Moench were carried out using aqueous extract from palm bunch ash of Elaeis guineensis Jacq. Various concentrations of palm bunch ash extract; 10, 20, 30, 40, and 50\%, alongside a control (0\%) were used. The extract was used to study the germination percentage, coefficient of velocity of germination, shoot length, root length, fresh weight, dry weight, and moisture content of the crop. Analysis of the extract revealed a $\mathrm{pH}$ value within an alkaline range of 9.1, and the presence of mineral elements such as calcium, potassium, magnesium, sodium, iron, copper, total nitrogen and zinc. The percentage germination of the crop decreased significantly $(P<0.05)$ with increase in concentration of the extract, except at low level (10\%) where there was an increase above the control. The fresh weight and moisture contents of the crop were slightly stimulated above the control at 10\% level of the extract, and decreased with increase in concentration at higher levels of the extract. The shoot length, root length, and dry weight of the crop decreased significantly $(P<0.05)$ with increase in concentration of the extract. Palm bunch ash extract may inhibit germination and growth of Abelmoschus esculentus at higher concentration. However, in view of the mineral nutrient composition of the extract, optimum dosage should be worked out for its utilization as organic manure, most especially in acidic soils under field condition.
\end{abstract}

Key words: Germination, Growth, Abelmoschus esculentus L. Moench, Palm bunch ash extract, Elaeis guineensis Jacq

\section{Introduction}

Organic manure is utilized as a source of nutrients for plant growth and a soil amendment for improvement of soil structure and texture [1];[2]. Organic manure has the potential of providing increased physical and biological storage mechanisms of soils. Similarly, organic manure is an excellent natural fertilizer containing nitrogen, phosphorus, potassium, and other nutrients as well as its organic matter content, which improves soil structure, aeration, soil moisture holding capacity and water infiltration [3]. In addition, improved organic matter content of the soil serves as a source of food and energy for a myriad of beneficial soil microorganisms. Although, the nutrient content of organic manure varies depending on source, moisture content, storage, and handling methods, the general application rates are based on both soil and crop needs. Nutrient disorders may be noticeable on plants due to nutrient toxicity resulting from too much of available nutrient or as nutrient deficiency to plant [4];[1];[3]. Therefore, the nutrient content of the soil and nutrient requirements of the crop should be carefully balanced with application of nutrient.

Oil palm (Elaeis guineensis Jacq) is a species of palm commonly called African oil palm, which is highly cultivated in southern Nigeria as the principal source of edible palm oil. Empty fruit bunch is one of the major waste products generated from processing fresh fruit bunch in palm fruit processing mills. The empty palm fruit bunches are often burnt or put through a special incineration process to produce palm bunch ash [5];[6];[7]. The filtrate (palm bunch ash extract), an aqueous extract commonly used for domestic purposes in most part of southern Nigeria, which is obtained from the filtration of the mixture of palm bunch ash and water has a brown colour, slippery to touch, and can emulsify oil [8]. Palm bunch is used by farmers as one of the best and the most economical sources of potassium. Its high $\mathrm{pH}$ value makes it a useful material for neutralizing soil acidity, especially in peat areas and acidic soils with low potash. In addition, the rich content of potassium, calcium, phosphorus and magnesium in the palm bunch ash, makes it suitable as a liming material and fertilizer supplement [9];[8].

Abelmoschus esculentus L. Moench belongs to the family Malvaceae. It is a popular vegetable crop cultivated widely in the tropics and some parts of the subtropics mainly for its fruit, which is used as a vegetable both in the green and dried state. It is an important cash crop for small and marginal farmers [10];[8]. This research becomes greatly significant in view of the fact that most soils in Southern Nigeria are deficient in nutrients as well as acidic due to the nature of parent material, heavy leaching and weathering [11]. This 
research was conducted to examine the effect of Aqueous extract obtained from palm bunch ash of Elaeis guineensis Jacq on the germination and growth of Abelmoschus esculentus L. Moench

\subsection{Preparation of Palm Bunch Ash}

\section{Materials and Methods}

Palm bunch refuse were obtained from local oil palm mills sites in Abak, Akwa Ibom State, Nigeria. The palm bunch refuse were sundried for one week and ashed in the oven at $100^{\circ} \mathrm{C} .250 \mathrm{ml}$ of distilled water was used to extract $100 \mathrm{~g}$ of palm bunch ash under continuous heating and stirring (30 mins) on a mechanical shaker. The slurry obtained from the process was centrifuged (1000 r/min, 15 mins) filtered under vacuum (using Bunsen burner) and freeze dried to obtain aqueous extract (17). The aqueous extract was diluted using distill water to obtain 10,20,30,40 and 50\% concentrations of palm bunch ash extract while $0 \%$ (distilled water) served as a control.

\subsection{Germination Studies}

Seeds of Abelmoschus esculentus L. Moench were obtained from Akwa Ibom Agricultural Development Programme (AKADEP), Uyo, Akwa Ibom State, Nigeria. Healthy seeds were surface sterilized with $0.01 \%$ mercuric chloride for 30 seconds. Sterilized seeds were immediately washed several times with sterile distilled water and air dried. Seeds (10) of the crops were sown in sterilized Petri dishes each containing two sterile What-Man's filter paper. Each treatment was replicated five (5) times and maintained for 21 days under light condition at $28 \pm 1^{\circ} \mathrm{C}$. Percentage germination and coefficient of velocity of germination counts were recorded at 24, 48, 72, and 96 hours after sowing all the seeds (17).

\subsection{Growth studies}

Growth parameters such as shoot length, root length, fresh weight, dry weight, and moisture content of the seedlings were measured as follows:

\subsubsection{Determination of Germination Percentage and Coefficient of Velocity of Germination}

Percentage germination and coefficient of velocity of germination counts were recorded at 24, 48, 72 and 96 hours after sowing all the seeds [12].

Germination Percentage : $\frac{\text { Number of seeds germinated }}{\text { Total number of seeds sown }} \times \frac{100}{1}$

Coefficient of Velocity of Germination : Total number of seedlings

$\mathrm{A}_{1} \mathrm{~T}_{\mathrm{I}}+\mathrm{A}_{2} \mathrm{~T}_{2}-\cdots \mathrm{A}_{\mathrm{X}} \mathrm{T}_{\mathrm{X}}$

Where $\mathrm{A}=$ the number of seedling emerging on a particular number of days- $(\mathrm{T})$

\subsubsection{Determination of Shoot Length and Root Length}

The shoot length and root length of the seedlings were measured with a meter rule and expressed in centimeters.

\subsubsection{Determination of Fresh Weight, Dry Weight, and Moisture Content}

Seedlings were harvested at the end of experiment (21 days). Harvested seedlings were washed with sterile-distilled water using a sieve to avoid loss of plant parts. Blotting papers were used to dry the seedlings and the fresh weight measured using mettler-p- 165 weighing balance. Gallen Kamp oven maintained at $65^{\circ} \mathrm{C}$ was used to dry the fresh seedlings for 2 days followed by measurement of dry weight. The percentage moisture content of the seedlings was obtained as the difference between the fresh weight and dry weight of the plantlets multiplied by 100 over the fresh weight [13].

\subsection{Analysis of Palm Bunch Extract}

The $\mathrm{pH}$, and mineral element (calcium, magnesium, potassium, sodium, zinc, copper and iron) contents of palm bunch ash extract were examined using atomic absorption spectrophotometer [14].

\subsection{Statistical Analysis}

The data generated from the study were subjected to analysis of variance (ANOVA) where the differences in the means were tested using Least Significant Difference (LSD) [15].

\section{Results and Discussions}


The $\mathrm{pH}$ of the palm bunch ash extract was 9.10 indicating that it is an alkaline medium. Similarly, the palm bunch ash extract showed the presence of potassium, calcium, magnesium, sodium, copper, iron, zinc, and total nitrogen in a decreasing order as mineral elements (TABLE 1). The rich mineral composition of the extract shows that it can be utilized as nutrient supplements to improve the soil fertility, as well as its effectiveness as a liming material due to the alkaline properties. Palm bunch ash has been reported to contain varying nutrient content depending on the source and method of treatment [16]. Increase in available nitrogen, phosphorus, potassium, calcium and magnesium has been reported in palm bunch ash treated soils [9].

Table 1: $\mathrm{pH}$ and Mineral Element Content of Palm Bunch Ash Extract

\begin{tabular}{l|l}
\hline Parameters & Content \\
\hline $\mathrm{pH}$ & 9.10 \\
Calcium & $15.20 \mathrm{mg} / \mathrm{l}$ \\
Magnesium & $12.33 \mathrm{mg} / \mathrm{l}$ \\
Potassium & $30.02 \mathrm{mg} / \mathrm{l}$ \\
Sodium & $7.08 \mathrm{mg} / \mathrm{l}$ \\
Zinc & $0.36 \mathrm{mg} / \mathrm{l}$ \\
Copper & $0.63 \mathrm{mg} / \mathrm{l}$ \\
Iron & $0.42 \mathrm{mg} / \mathrm{l}$ \\
Total nitrogen & $0.14 \%$ \\
\hline
\end{tabular}

Germination studies showed that the percentage germination of Abelmoschus esculentus significantly $(\mathrm{P}<0.05)$ decreased with increase in concentration of palm bunch ash extract, except at $10 \%$ level of concentration, where there was a slight stimulation above the control. Similarly, the coefficient of velocity of germination of the crop decreased with increase in the concentration of the extract (TABLE 2).

Osmotic pressure effect has been identified as one of the major factors that affect germination and growth of crops in palm bunch ash treated medium [17]. High osmotic pressure of a medium causes difficulty in absorption of water and nutrients by plant roots which results in growth retardation [4];[18].

Table 2: Effect of Palm Bunch Ash Extract on the Germination Percentage and Coefficient of Velocity of Germination of Abelmoschus esculentus

\begin{tabular}{|c|c|c|c|c|c|c|c|c|}
\hline $\begin{array}{l}\text { Concentration } \\
\text { of PBAE }(\%)\end{array}$ & 0 & 10 & 20 & 30 & 40 & 50 & Mean & $\begin{array}{r}\text { LSD } \\
(\mathrm{P}<0.05) \\
\end{array}$ \\
\hline $\begin{array}{l}\text { Germination } \\
\text { Percentage }(\%)\end{array}$ & $82.00 \pm 0.31$ & $84.00 \pm 0.92$ & $76.00 \pm 0.24$ & $68.00 \pm 0.41$ & $64.00 \pm 0.39$ & $52.00 \pm 0.21$ & 71.00 & 2.04 \\
\hline $\begin{array}{l}\text { Coefficient of } \\
\text { Velocity } \\
\text { Of Germination }\end{array}$ & 0.22 & 0.21 & 0.21 & 0.18 & 0.18 & 0.17 & 0.20 & 0.12 \\
\hline
\end{tabular}

Mean value \pm Standard error of 5 replicates

In this study, the shoot length, root length, fresh weight, dry weight and moisture content of the crop were significantly $(\mathrm{P}<0.05)$ decreased with increase in the concentration of palm bunch ash extract, except at $10 \%$ concentration, where there was slight stimulation in fresh weight and moisture content of the crop (Table 3). The incorporation of liming material into the soil to correct soil acidity has shown a number of beneficial effects such as aggregation of soil particles and rate of organic matter decomposition [19];[20];[21]. This study has revealed both growth deterioration and enhancement of some growth parameters of the crop at higher and lower concentrations of the extract, respectively. In general, the most favourable $\mathrm{pH}$ range for vegetable is between 5.5 to 6.5 in mineral soil and 5.0 to 6.0 in organic soil, therefore, the availability of some plants nutrients is greatly affected by soil $\mathrm{pH}$ [22]. At alkaline $\mathrm{pH}$ values greater than 7.5, phosphates ions tend to react with calcium and magnesium to form less soluble compounds. Most of the other nutrients, especially some micronutrients such as boron, manganese, iron, zinc, and copper, tends to be less available at soil $\mathrm{pH}$ above 7.5 such that these nutrients are precipitated as solid materials that plants cannot use [4];[23]. Excessive liming has also been shown to cause prominent nutrient disorders such as chlorosis resulting from elevated levels of bicarbonate concentration. High level of bicarbonate may lead to decrease growth and yield of crops due to distortion in uptake, translocation, and utilization of trace elements such as iron as well as inhibition of leaf growth and chloroplast development [22];[19];[18]. 
Table 3: Effect of Palm Bunch Ash Extract (PBAE) on the Growth Parameters of Abelmoschus esculentus

\begin{tabular}{|c|c|c|c|c|c|c|c|c|}
\hline $\begin{array}{l}\text { Concentration } \\
\text { of PBAE }(\%)\end{array}$ & 0 & 10 & 20 & 30 & 40 & 50 & $\begin{array}{l}\text { Mean } \\
\qquad(\mathrm{P}<\end{array}$ & $\begin{array}{l}\text { LSD } \\
05)\end{array}$ \\
\hline Shoot Length $(\mathrm{cm})$ & $14.20 \pm 0.27$ & $12.60 \pm 0.14$ & $10.20 \pm 0.22$ & $9.30 \pm 0.14$ & $8.40 \pm 0.24$ & $7.50 \pm 0.12$ & 10.37 & 1.97 \\
\hline Root Length $(\mathrm{cm})$ & $6.10 \pm 0.43$ & $5.20 \pm 0.17$ & $4.30 \pm 0.19$ & $3.20 \pm 0.30$ & $2.80 \pm 0.23$ & $2.30 \pm 0.15$ & 3.98 & 1.24 \\
\hline Fresh Weight (g) & $1.42 \pm 0.20$ & $1.44 \pm 0.12$ & $1.20 \pm 0.18$ & $1.07 \pm 0.44$ & $0.94 \pm 0.06$ & $0.79 \pm 0.07 \quad 1.14$ & $4 \quad 1.1$ & \\
\hline Dry Weight (g) & $0.25 \pm 0.03$ & $0.21 \pm 0.06$ & $0.20 \pm 0.05$ & $0.20 \pm 0.02$ & $0.19 \pm 0.06$ & $0.16 \pm 0.02 \quad 0.20$ & 1.02 & \\
\hline Moisture & $82.39 \pm 0.52$ & $85.42 \pm 0.62$ & $83.33 \pm 0.43$ & $81.31 \pm 0.277$ & $79.79 \pm 0.46$ & $79.75 \pm 0.2482 .00$ & 2.72 & \\
\hline
\end{tabular}

Content $(\%)$

Mean value \pm Standard error of 5 replicates

\section{Conclusion}

The effective use of palm bunch ash extract as nutrient supplement and liming material in acidic soil requires the application of the extract at optimum rates as well as identifying both crop and soil needs, most especially for the cultivation of Abelmoschus esculentus L. Moench. Higher concentrations of palm bunch ash extract may negatively affect germination and early seedling growth of the test crop (Okra).

\section{Acknowledgements}

I wish to appreciate the contributions from Mr. Isaac Udo Isaac, the Senior Technologist, Department of Chemistry, and Mr Awolabi Akeem, Department of Biological Sciences, Faculty of Science, Federal University Otuoke, Bayelsa State. Iam indepted to all authors whose materials have been used to produce the literatures and other parts this work.

[1]. Traunfeld J., Soil amendments and fertilizer, fertilizing guidelines included by plant group (University of Maryland Extention: http://extension.umd.edu/sites/default/files/images/proqasus/hqic/publications/HG42-soilamendments-and-fertilizers.pdf. Accessed September 29, 2014, 2013).

[2]. Etukudo M. M, Nwaukwu I. A, Habila S, The effect of sawdust and goatdung supplements on growth and yield of okro (abelmoschus esculentus L. Moench) in diesel oil contaminated soil, Journal of Research in Forestry, Wildlife and Environment,(2)3,2011,92-98.

[3]. Walliser, J., Quick guide,10 natural fertilizers to improve crop production (http://www.hobbyfarms.com/cropproduction.aspx.,accessed September 29, 2014, 2013)

[4]. Anoliefo, C. O, Introductory tropical plant biology (Nigeria: Uniben Press, 2006)

[5]. Ataga C.D, and Van-der-vossen H.A.M, Elaeis guineensis jacq in Van -der-Vossen H.A.M \& Mkamilo G.S (Ed.), Vegetable oils/oleagineux (Wageningen, Netherlands: cd-rom prota, 2007)

[6]. Basiron, Y, Jalani, B.S, Chan, K.W., Advances in oil palm research, volume I \& II (Kuala Lumpur, Malaysia: Malaysian Palm Oil Board Ministry of Primary Industries, 2000)

[7]. $\quad$ Corley R.H.V and Tinker P.B, The oil palm (Oxford, United Kingdom: Blackwell Science, 2009)

[8]. Udoetok I.A, Charactrization of ash made from oil palm bunch empty fruit bunches, International Journal of Environmental Sciences,(1)3, 2012,518-524.

[9]. Awodun M.A, Ojeniji S.O, Adeboye A, Adedina S. A., Effect of oil palm bunch refuse ash on soil and plant nutrient composition on yield of maize, Am.Eurasian Journal of Sustainable Agriculture, (3),2007,50- 54.

[10]. Dhankhar B.S, Singh R., Okra handbook, global production, processing, and crop improvement( www.agronomy.org> publications> booksreviews accessed September 29, 2014: HNB publishing, 2009)

[11]. Owolabi O, Adeleye A, Oladejo O.T, Ojeniji, S.O., Effect of wood ash on soil fertility and crop yield in south western Nigeria, Nigerian Journal of Soil Science, (13),2003, 55- 60.

[12]. Esenowo, G. J, Developmental biology and plant physiology (Nigeria: Abaam Publishing Co, 2001)

[13]. Pajevic, S., Vasic, D., and Sckulic, P., Biochemical characteristics and nutrient content of callus of sunflower inbred lines, Helia, (41)27, 2004, 143-150.

[14]. A.O.A.C, Official methods of analysis (Association of official analysis chemists: Washington D. C. Press, 1990)

[15]. Obi, 1. U., Statistical methods of detecting differences between treatment means and research methodology issues in laboratory and field experiments (Nigeria: AP Express publishers limited, 2002)

[16]. Abdullah I.N, Sulaiman F, Gerhauser H., Characterization of oil palm empty fruit bunches for fuel application, Journal of Physical Sciences (1)22,2011,1-24.

[17]. Onwugbuta-Enyi J, Offor U.S, Effect of palm bunch ash on the seed germination, seedling growth and biochemical parameters of soyabeans, Journal of Agriculture and Social Research, (1)10, 2010

[18]. Whiting .D, Wilson C, Reeder J., Soil pH- colorado master gardener program-cmg garden notes ( http://www.ext.colostateredu/mg/gardennotes/222.html accessed september 30, 2014, 2011)

[19]. Etukudo M.M, Roberts E.M.I, Omeje F. Early seedling growth and development response of Zea mays L. to extract from palm bunch ash (PBAE) of elaeis guineensis Jacq.International Journal of Recent Scientific Research (7)5,2014,1307-1310.

[20]. Ezekiel P.O, Ojeniyi S.O, Asawalam D.O, Ano A.O., Effect of oil palm bunch ash and soil npk on root yield of sweet and bitter cassava, Nigerian Journal of Soil Science,(19),2009, 1- 10.

[21]. Offor U.S, Wilcox G.J, Agbagwaa C.N., potentials of palm bunch ash on yield of zea mays. Journal of Agricultural and Social Research, (2)10, 2010, 132-134.

[22]. Agbede, O. O, Understanding soil and plant nutrition (Nigeria: Salmon Press and Co. Ltd, 2009)

[23]. Jensen T.L., Soil pH and the availability of plant nutrients (International Plant Nutrition Institute : www.ipni.net/pnt. accessed september 30, 2014, 2010) 